\title{
The Influence of Technology and Innovation in Online Teaching Arabic as a Second Language in Dubai
}

\author{
Mohamed Moghazy \\ School of Education, University of Illinois, Urbana and Champaign PO box 121306, Dubai, UAE
}

\begin{abstract}
Arabic as a second language (ASL) is an upcoming social exploration area in Dubai and the larger UAE (Alfataftah \& Jarrar, 2018). However, there is insufficient literature on the subject. Teaching and learning ASL is the subject of increasing controversy. Amara (2017) states that Arabic is the official language in the UAE; however, most of the population speaks English because UAE was a British colony until 1971. Given that the $\mathrm{UAE}$ is one of the Arab countries, the Arabic language is one of the national curriculum's key subjects apart from Social Studies and Islamic Education. According to AlHagbani and Khan (2016), there has been an increased significance of teaching the Arabic language for non-Arabic speakers in the UAE over the last few years. Besides, the main objectives are developing an awareness of learners about relationships between the Arabic language and Arabic or Islamic culture, enhancing awareness of the need for the Arabic language across the world, and improving both oral and written communication skills to strengthen the process of obtaining informational literacy level. One divide argued that Arabic was a dying language in the Middle East in the face of the globalized English language, according to Sabbah (2016). Different studies (Cook, 2016; Carroll, Al Kahwaji, \& Litz, 2017) indicate that the other controversial divisions argued that the Arabic language was a growing language in the UAE.
\end{abstract}

Keywords: technology, online learning, online teaching, motivation, Arabic as a second language, Dubai

DOI: $10.7176 / \mathrm{JEP} / 12-5-08$

Publication date: February $28^{\text {th }} 2021$

\section{Introduction}

Kennetz and Carroll (2018) demystified the Arabic language threat in the UAE and the propagations that Arabic was fading. The more extraneous debates around the Arabic language have perceived extinction. Kennetz and Carroll (2018) indicated that the UAE population's steady growth had increased linguistic, education, and cultural diversity in the UAE, especially in major cities like Dubai and Abu Dhabi. Despite the growth and the accoladed diversity, the Arabic language is spoken by $10 \%$ to $15 \%$ of the total population, thus making the residents and scholars among other interested parties wary, often deteriorating the Arabic language trend in the UAE.

However, Bin-Samah et al. (2016) noted that teaching and learning Arabic face innumerable challenges that curtail the Dubai and UAE government's efforts in promoting Arabic literacy. Alkutich (2017) noted that the ASL curriculum presents many challenges, while Belhiah and Elhami (2015) noted competition from English. Kataw (2016) noted limited teaching and learning time, vernacular, and colloquialism. Similarly, Alkahtani (2019), Hadi (2019), Mosa and Kakehi (2015), and Mustaffa, Sharif, Sirri, and Hj-Salam (2019) noted that technology was a significant challenge in teaching and learning ASL.

However, there are dismal learning and teaching outcomes, thus arousing the researcher's interest in the practice's challenges. Salama (2017) noted that the UAE government had reshuffled places, systems and increased efforts to bolster the Arabic language to enhance businesses, interactions, and innovations. Further, Bernikova and Redkin (2017) added that increased linguistics integration and proliferation increased the need to explore ASL's practice and learning in Dubai. Therefore, based on the background information, this literature review will critically synthesize and analyze sources that have explored the concept related to "What is the role of innovation and technology infusion in teaching ASL?"

\section{Issue/topic/theme}

The main issue to be examined is the influence of technology and innovation in ASL in Dubai. Faryadi (2007) examined interactive media's role in teaching the Arabic language and discovered that technology integration allows instructors to improve their lessons based on achieving effectiveness and creativity in knowledge transfer. Learners are easily persuaded to reason and think critically in the classrooms through interactive media.

Nevertheless, Almekhlafi and Almeqdadi (2010) conducted a study that sought to examine teachers' perceptions of technology integration into the classroom setting and found out that technology-based educational techniques enable teachers to emphasize using the application and metacognitive skills in different academic content areas. Ishtaiwa \& Shana (2011) further stated that teaching the Arabic language can be enhanced by using an interactive whiteboard that offers teachers opportunities to implement different strategies to enhance the learners' understanding. An interactive whiteboard is beneficial in different ways, including using presentation 
tools, enabling a teacher to write notes over education video clips, viewing content as a group, providing indefinite storage space, and allowing creative and dynamic web-based integration and replicate older functions of presentation materials. Arrabtah and Nusour (2012) further reveal that technology and innovative techniques can teach Arabic language grammar. However, critical considerations should be given to how the students comprehend the junk of information gathered from different e-learning tools.

On the other hand, Engin (2014) persists in extending the flipped classroom model and suggesting that student-created digital video can foster the skills while teaching the second language. Although, Abedalla (2015) propagated that students' perceptions regarding the use of mobile applications technology can affect teaching as some may not concentrate on what the instructor is providing but instead focus on other activities such as social media. Al Musawi et al. (2016) disagrees with the previous discoveries by indicating that Arabic language teachers can utilize traditional and technology-based interventions to teach ASL. Gharawi and Bidin (2016) further argue that computer-assisted language teaching techniques facilitate students' ability to gain more experience.

English to increase their prospects in the global economy, where English is the primary medium of communication. Likewise, Kennetz and Carroll's (2018) findings disapproved of Sabbah's (2015) assertions in the examination of whether Arabic was a fading language. Further, Muro (2019) explored the media's rhetorical scrutiny of Arabic and English struggle. Muro (2019) depicted that most indigenous dialects are on the verge of extinction, thus making cultural heritage stakeholders document fading language. Muro (2019) further added that although Arabic in the UAE was not a fading language as earlier propagated by some researcher such as $\mathrm{Al}$ Oraimi (2017), Cook (2016), and Hopkyns (2017), the decreasing trend and influence of the immigrants and western world in most gulf countries warranted scientific scrutiny.

Some of the most cited authors and researchers in teaching and learning the Arabic language can be found in the literature regarding Arabic diglossia, triglossia, technology in Arabic, vocabulary aspects of Arabic, and perceptions of learners, teachers, and Arabic policymaking. Such researchers included Ryding (2013), Wekke (2015), Palmer (2007), Bin-Tahir, Saidah, Mufidah, and Bugis (2018), Ferrari (2018), Alkutich (2017), and Ahmad (2018). The elucidations above were informed by scrutinizing the most cited scholarly sources on major scholar archives such as Google Scholar and Google Books. However salient trend was that most researchers explored a variety of sources to enrich their explorations. Notably, there are innumerable authors (Alhaqbani \& Riazi, 2012); Alfaifi, Atwell \& Hedaya, 2014; Alasraj \& Alharbi, 2014) cited in scientific research examinations of teaching and learning of ASL and related concepts. However, their works cannot be explained exhaustively in this review.

\subsection{Synthesis of Key Concepts and Theoretical Concepts}

The key concepts to be considered include technology integration and its impact on teaching, the factors that influence innovation, and technology diffusion in foreign language teaching. Furthermore, new teaching techniques include learning video-clips, listening to CD-players, chatting and email messaging programs, electronic dictionaries, presentation software, computer-assisted language learning programs, and language learning websites. The researchers who made significant attempts to explain these concepts are as follows; Joshi (2012) assessed the innovative techniques to engage learners and suggested transforming the teaching programs across the UAE. Similarly, Dajani (2015) insists on stimulating creativity in teaching the Arabic language and using interactive tools to improve learners' skills.

On the other hand, Palfreyman and Karaki (2017) inspected Arabic and English concepts as the main languages of pedagogic instruction in the UAE education acumen. Almekhlafi and Almeqdadi (2010) assessed teachers' perceptions regarding technology integration and how it can be an effective strategy in teaching SL. Aburezeq and Ishtaiwa (2013) focus on the social media networks' primary WhatsApp and its impact on interaction in Arabic language teaching. Alasraj and Alharbi (2014) examined the effectiveness of computeraided technologies in teaching ASL. Similarly, Wahdah (2018) assessed the learning strategy concepts of Arabic and relating issues, while Baus and Costa (2016) evaluated second language processing issues and concepts.

Moreover, Gharawi and Bidin (2016) and Batainah, Din, and Al Mashakbh (2018) scrutinized computeraided and hybrid ASL learning aspects and teaching and learning issues ASL, respectively. Likewise, O'Sullivan (2017), Zakaria, Atan, and Robe'ah-Yusuf (2019) and Jwaifell, Abu-Omar, and Al-Tarawneh (2018) focused on the professional development of trainer aspects of ASL pedagogy based on innovative and technology-based interventions while Carroll et al. (2017), Shendy (2019), Alfaisal and Aljanada (2019) and Saiegh-Haddad and Ghawi-Dakwar (2017) technology integration or diffusion barriers. Similarly, Haron, Ahmed, Mamat, Ahmad, and Rawash (2016) and Kennetz and Carroll (2018) examined multimedia software's efficacy in teaching ASL based on computer-assisted programs. Alkutich (2017) also investigated the efficacy of the innovation infusion in solving curriculum delivery constraints in ASL teaching, focusing on the UAE institutions.

A review of the key theoretical frameworks used in the sources depicted varied assumptions and theoretical postulations regarding ASL's teaching and learning. Different studies use various theoretical frameworks to 
achieve the objectives of the research. Several studies (Imenda, 2014; Haron et al., 2016; Taha, 2019; Carroll et al., 2017; Harrison, 2018; Alkutich, 2017; Cook, 2016; O'Neill, 2017; Ahmad, 2018) used the interpretivism theoretical models. Interpretivism involves a fundamental research approach in sociology that integrates human interest in the study. Interpretivist paradigm reveals that, in all the research processes, the researcher's values are inherent because conflicting interpretations are negotiated. Dialogue helps to negotiate truth, and the interpretations are based on a particular moment. In the interpretivist model, qualitative methods are used, and the approach relies heavily on a naturalistic method, including analysis of the existing text, interviewing, and observation. Reality is socially constructed, considering relationships with other people, social settings, and culture.

Other studies (Belhiah and Elhami, 2015; Belhiah and Elhami, 2015; Mustaffa, Sharif, Sirri, and Hj-Salam, 2019; Bakry and Alsamadani, 2015; Salameh, 2018; Palfreyman and Karaki, 2017; Kennetz and Carroll, 2018) used the positivism research paradigm. Positivism is a research philosophy that focuses on factual knowledge obtained from observation or measurement, which is considered trustworthy. The researcher is limited to objective collection of data and interpretation. This theoretical belief is used to describe a study of society based on scientific evidence, including statistics and experiments revealing the true nature of how society operates. The positivist approach's main principles include human senses should be used to observe research empirically; the goal of inquiry is to discover, predict, and explain the logic of inquiry is identical. The philosophical assumption is that natural phenomena, their relations, and properties determine positive knowledge.

Al-Mohsen (2016) employed pragmatical theoretical underpinnings and frameworks in line with the mixed methods approaches and concepts utilized to inspect teachers' perceptions in teaching ASL using interrogated approaches. Pragmatism is described as the research paradigm that underpins most of the mix-method studies and is based on the idea that the research questions can be answered most effectively through the best methods. Thus, pragmatism is a problem-oriented philosophy that pays attention to the individual decision-maker.

The salient similarity in all the sources reviewed in this study revealed that each study used s theoretical framework that harmonized with the study's methodological underpinnings. Therefore, its methodology aspects and frameworks informed the type of theoretical framework adopted in the study. Notably, most researchers use positivism in line with quantitative methods or interpretivist frameworks in line with quantitative frameworks.

However, there is a small number that utilizes pragmatic theoretical assumptions and frameworks inline in mixed methods. Besides harmony among paradigm, theoretical frameworks, and methods, the review of the sources above showed that besides adopting a theoretical framework, positivist-oriented studies also had a conceptual framework to underpin the research process and findings.

\subsection{A Synthesis of Methodologies}

As noted in the preceding subsection above, methods and theoretical assumptions are interrelated. Al-Mohsen (2016) investigation utilized a mixed-method approach whereby the researcher conducted interviews and an Arabic teacher survey to examine teachers' perceptions regarding interpreted approaches of teaching ASL. AlMohsen (2016) surveyed 60respondents. The survey had 50 items that explored perceptions of teachers regarding varied aspects and concepts of ASL pedagogy. The triangulation of methods was essential in providing a more descriptive illumination of teacher's perceptions of ASL.

On the other hand, Haron et al. (2016) adopted a qualitative case study method to explore the challenges facing learning the Arabic language. The researcher s employed interviews and group discussions as the instruments to glean data from 14 participants. The researchers used different techniques to collect data to examine the challenges facing teaching and learning ASL. The researchers validated the investigation findings using multiple methods triangulation strategy using interviews and group discussions, examining peers, and enriched descriptions of results (Haron et al., 2016). A case study was justified in this investigation because the researcher examined the challenges facing learning a teaching Arabic language using Malay speakers. The focus on the Malay language was on harmony with a qualitative case study methodology. Alkutich (2017) utilized a qualitative method whereby four Arabic teachers and 6 ASL learners were interviewed using semi-structured questions to examine the constraints of the ASL curriculum and the resulting challenges in the practice of teaching ASL.

Notably, Alkutich (2017) conducted a pilot study using three teachers and one ASL teacher. The collected data were analyzed using thematic and content analysis. Moreover, Abdrabo (2018) used a qualitative phenomenological methodology where primitiveness theory, conventional theory, and theory of appraising were used to illuminate globalization's impacts on teaching Arabic trends. Alfataftah and Jarrar (2018) also adapted a qualitative ethnography where a historical chronology approach was merged with deductive and inductive approaches to illuminate challenges facing ASL pedagogy in the face of globalization. Amara (2017), Baharudin, and Ismail (2015), Baus and Costa (2016) used qualitative methodologies to illuminate second language processing.

Likewise, Shendy (2019) combined a qualitative ethnography and phenomenology to examine the 
challenges that young ASL learners experience and their struggle to read and write MSA. Seymour (2016), Saiegh-Haddad and Ghawi-Dakwar (2017), and Sabbah (2015) also used qualitative approaches to inspect the impacts and challenges associated with diglossia in learning and teaching MSA. O'Sullivan (2017) also used open-ended interviews to examine second language acquisition in the UAE, using Arabic as a case. The researcher focused on the role of teacher quality, experience, and professional development in learning and teaching ASL. O'Neill (2017) also used qualitative approaches and methods to inspect the subject. Similarly, Zainuddin and Sahrir, 2016) used social constructivism and second language acquisition theories to augment the qualitative methods in examining the teaching MSA vocabulary.

Additionally, Muro (2019) used a qualitative approach to conduct a rhetorical analysis of the controversy surrounding the notions that some languages cause others' extinction. Muro used a qualitative multicase study of English and Arabic to contextualize the examination. Additionally, Kennetz and Carroll (2018) used a qualitative approach to examine the UAE's language threat. However, Bakry and Alsamadani (2015) used a quantitative experimental design where the correlation coefficient was obtained using 12 sample participants to explicate the impacts of self-regulated strategies of learning ASL. Batainah et al. (2018) also used a quantitative method to examine the impacts of the ASL language's hybrid learning. Another researcher that used quantitative methodologies in this review included Jwaifell, Abu-Omar, and Al-Tarawneh (2018), Bin-Tahir et al. (2018), Ferrari (2018), and Wahdah (2018). Notably, a salient commonality in the sources reviewed is that most studies examining the learning and teaching of Arabic and related aspects employed qualitative methods. There were a few quantitative and mixed methods studies.

\section{Synthesis of Main Empirical Finding and Practical Implications}

Different researchers examined ASL challenges, whereby inadequate infusion of technology into the ASL curriculum was identified as the primary obstacle. The researchers include Alfataftah and Jarrar (2018), Hadi (2019), Alkutich (2017), Carroll et al. (2017), Palfreyman, and Karaki (2017), Baus and Costa (2016), and Haron and Ahmed (2016). Besides, learners should be motivated to use MSA in social interactions by comprehending the negative implications of diglossia on learning MSA. The findings also showed that Arabic was not a fading language as earlier propagated in a discourse of researchers such as Sabbah (2015), Muro (2019), Hopkyns (2017), Wahdah (2018).

Alkutich (2017) found out that there were conflicts between teaching and learning material available with the curriculum, limiting teachers' creativity and innovation. Another diverse testing system of ASL made it hard to teach ASL since the presence of The General Certificate of Secondary Education (GCSE), the International Baccalaureate (IB) diploma, Advanced level (A-Level), and ministerial systems complicated the curriculum and evaluation. The findings' implications were those policy stakeholders needed to craft a universal curriculum or harmonize the existing curriculums' provisional and guidelines to ensure that there was a level playground for all the teachers and learners.

In support of ASL in Dubai and the broader UAE, Cook (2016) explained that teaching modern standard Arabic (MSA) was essential in promoting Arabic as a dialect for science in Dubai. Additionally, Belhiah and Elhami (2015) found that English was rapidly becoming a priority language in instruction in most schools in Dubai and other major UAE cities. Taha (2019) and Dajani (2015) attributed the trend to the increasing immigrant population in the UAE. Besides, Belhiah and Elhami (2015) reveal that convolutions and debates exist about the universality of using the Arabic language for decisions in pedagogical institutions. Belhiah and Elhami (2015) ascertained that linguistic diversity, in most Gulf countries, accentuates the English language as a medium for communication.

\subsection{Gaps in the Literature}

Numerous studies (Sabbah, 2015; Palfreyman \& Karaki, 2017; Aburezeq \& Ishtaiwa, 2013) have focused on explaining to teach ASL but have failed to give a detailed analysis of practical techniques that can enhance the teaching processes. Instructors in the UAE still struggle and face challenges while teaching ASL. Students may feel demotivated due to a lack of interactive techniques that could enhance their Arabic language learning. Dajani (2015) recommends that innovative approaches need to be investigated to enable students to practice their developing skills through experience and listening to how Arabic is communicated outside the classroom boundaries. The virtual world and engaging learners in simulating can be beneficial, but this area has not been addressed adequately.

Nevertheless, further research should focus on using mobile devices to enhance teaching Arabic as a second language. Haron et al. (2016) argue that teachers can access multiple apps to foster instructional classes. Another area includes a blended learning strategy that stimulates the application of diverse strategies based on integrating tech tools in teaching ASL.

Furthermore, according to Harrison (2018), the benefits also need to be examined in detail and teachers' and learners' perceptions on the impact of the innovation and technology factors in teaching ASL. Therefore, there is 
a research gap on technology infusion in ASL and the role of motivation in teaching and learning ASL. Other aspects or issues that require further illumination include perceptions of teachers and learners regarding Arabic, the role of motivation and technology aspects, and issues revolving around its adoption in ASL classroom instruction.

\section{Conclusion}

The literature reveals that innovation and technology diffusion has a significant impact on the teaching process of ASL. Teachers continue to implement different technology-based instruction tools that are likely to engage students and equip them with a wide range of skills and experiences. Computer-aided teaching techniques in ASL can offer diverse opportunities as the technologically mediated activities can foster language skills. Arabic instructors are required to integrate useful innovative approaches to enhance understanding of complex topics. Numerous challenges have hindered effective teaching of ASL, and scholars need to socially examine how to overcome them significantly by focusing on the different technology-based techniques. As a result, the current study will identify innovation and technology's role in enhancing motivation and teaching ASL in the UAE, particularly in Dubai.

\section{References}

Abdrabo, N. (2018). Globalization of the Arabic alphabet: Influences on contemporary European languages globalization of the Arabic alphabet. IOSR Journal of Humanities And Social Science (IOSR-JHSS), 20, 105-109

Abdullahi, A., Maliki, M., Rouyan, N., Noor, S., Halim, Z., Elhudaibiy, A., \& Bashir, F. (2019). Arabic vocabulary needed by Malay learners of Arabic as a foreign language. Trends in Social Sciences, 1(3), 3234.

Abedalla, R. W. (2015). Students' perceptions of the use of mobile applications technology in learning Arabic as a second language (Doctoral dissertation, Robert Morris University).

Aburezeq, I.M. and Ishtaiwa, F.F., 2013. The impact of WhatsApp on interaction in an Arabic language teaching course. International Journal of Arts \& Sciences, 6(3), 165.

Al Musawi, A., Al Hashmi, A., Kazem, A. M., Al Busaidi, F., \& Al Khaifi, S. (2016). Perceptions of Arabic language teachers toward their use of technology at the Omani basic education schools. Education and Information Technologies, 21(1), 5-18.

Al Oraimi, S. Z. (2017). Cultural Diversity and Social Cohesion in the United Arab Emirates. Paper Presentation at Addressing Inequalities, Mobility, and Dislocation: Insights from International and Domestic Research and Practice. Michigan State University, June 12.

Alasraj, A., \& Alharbi, H. (2014). The effectiveness of blended learning in teaching Arabic as a second language. International Journal of Research in Humanities and Social Studies, 1(1), 13-17.

Alfaifi, A. Y. G., Atwell, E., \& Hedaya, I. (2014, June). Arabic learner corpus (ALC) v2: A new written and spoken corpus of Arabic learners. In Proceedings of Learner Corpus Studies in Asia and the World 2014 (Vol. 2, pp. 77-89). Kobe: Kobe International Communication Center.

Alfaisal, A., \& Aljanada, R. (2019). Diglossia in Arabic: Views and Opinions. The International Journal of Humanities \& Social Studies, 7(5).

Alfataftah, G., \& Jarrar, A. (2018). Developing languages to face challenges of globalization and clash of civilizations: Arabic language as an example. Journal of Education and Learning, 7(4), 247.

AlHagbani, E. S., \& Khan, M. B. (2016). Challenges facing the development of arabic chatbot. In first international workshop on pattern recognition. International Society for Optics and Photonics.

Alhaqbani, A., \& Riazi, M. (2012). Metacognitive awareness of reading strategy use in Arabic as a second language. Reading in a foreign language, 24(2), 231-255.

Alkahtani, A. (2019). Learning the Arabic language in the age of computing between reality and hope: Ambition and challenges. Bioscience Biotechnology Research Communications, 12(1), 157-164.

Alkutich, M. (2017). Curriculum delivery constraints of Arabic language as a foreign language in the UAE. International Journal of Science and Engineering Applications, 6(9), 241-247.

Almekhlafi, A. G., \& Almeqdadi, F. A. (2010). Teachers' perceptions of technology integration in the United Arab Emirates school classrooms. Journal of Educational Technology \& Society, 13(1), 165-175.

Al-Mohsen, A. (2016). Arabic Teachers' Perception of an Integrated Approach for Teaching Arabic as a Foreign Language in Colleges and Universities in the United States (Ph.D.). San Francisco: The University of San Fransisco.

Amara, M. (2017). Challenges of Arabic language education policies in the Arab World. In the Routledge Handbook of Arabic Linguistics (pp. 546-559). London: Routledge.

Arrabtah, A., \& Nusour, T. (2012). Using Technology for Teaching Arabic Language Grammar. Journal of International Education Research, 8(4), 335. 
Baharudin, H., \& Ismail, Z. (2015). Learning strategies of Arabic language vocabulary for pre-university students' in Malaysia. Asian Social Science, 11(10).

Bakry, M., \& Alsamadani, H. (2015). Improving the Persuasive essay writing of students of Arabic as a foreign language (AFL): effects of self-regulated strategy development. Procedia - Social and Behavioral Sciences, 182, 89-97.

Batainah, R.A., Din, R., and Al Mashakbh, A., (2018). Hybrid personalized Arabic language learning. Journal of Personalized Learning, 2(1), 58-72.

Baus, C., \& Costa, A. (2016). Second language processing: Why another special issue? Language Learning, $66(\mathrm{~S} 2), 7-12$.

Belhiah, H., \& Elhami, M. (2015). English as a medium of instruction in the Gulf: When students and teachers speak. Language Policy, 14(1), 3-23.

Bernikova, O., \& Redkin, O. (2017). Linguistic diversity in the United Arab Emirates: History and perspectives. B 4th International Multidisciplinary Scientific Conference on Social Sciences and Arts SGEM 2017, Book 3 (p. 811-816).

Bin-Samah, R., Puteh-Behak, F., Mat Saad, N., Mohd Ali, S., Darmi, R., \& Harun, H. (2016). Effective methods in learning Arabic language as a foreign language. Mediterranean Journal of Social Sciences, 5(4), 33.

Bin-Tahir, S. Z., Saidah, U., Mufidah, N., \& Bugis, R. (2018). The impact of translanguaging approach on teaching Arabic reading in a multilingual classroom. Ijaz Arabi Journal of Arabic Learning, 1(1).

Carroll, K., Al Kahwaji, B., \& Litz, D. (2017). Triglossia and promoting Arabic literacy in the United Arab Emirates. Language, Culture and Curriculum, 30(3), 317-332. doi: 10.1080/07908318.2017.1326496

Cook, W. (2016). More vision than renaissance: Arabic as a language of science in the UAE. Language Policy, $16(4), 385-406$.

Dajani, B. (2015). Teaching the Arabic language: towards a new beginning that stimulates creativity. Procedia Social and Behavioral Sciences, 192, 758-763.

Dajani, B.A.S., 2015. Teaching Arabic Language: Towards a New Beginning that Stimulates Creativity. Procedia-Social and Behavioral Sciences, 192, 758-763

Engin, M. (2014). Extending the flipped classroom model: Developing second language writing skills through student-created digital videos. Journal of the Scholarship of Teaching and Learning, 12-26.

Faryadi, Q., 2007. Techniques of Teaching Arabic as a Foreign Language through Constructivist Paradigm: Malaysian Perspective. Malaysia: UiTM.

Ferrari, G. (2018). Teaching and learning Arabic variation through vocabulary. Doctoral Thesis, University of Exeter.

Gharawi, M., \& Bidin, A. (2016). Computer assisted language learning for learning Arabic as a second language in Malaysia: Teacher perceptions. International Journal of Information and Education Technology, 6(8), 633-637.

Hadi, N. (2019). Difficulties of the curriculum 2013 implementation in the Arabic language at Madrasah Ibtidahyah/ Kesulitan Implementasi Kurikulum 2013 Mapel Bahasa Arab Pada Madrasah Ibtidaiyah. Ijaz Arabi Journal of Arabic Learning, 2(1).

Haron, S., Ahmed, I., Mamat, A., Ahmad, W., \& Rawash, F. (2016). Challenges in learning to speak Arabic. Journal of Education and Practice, 7(24). Retrieved from https://files.eric.ed.gov/fulltext/EJ1112863.pdf

Harrison, M. (2018). Second language writing pedagogy in Middle Eastern contexts. The TESOL Encyclopedia of English Language Teaching, 1-7.

Hopkyns, S. (2017). Emirati cultural identity in the age of 'englishisation': voices from an Abu Dhabi university. In Louisa Buckingham (ed.), The place of English in Societies of the Arabian Gulf, 87-115. Bristol, UK: Multilingual Matters.

Imenda, S. (2014). Is there a conceptual difference between theoretical and conceptual frameworks? Journal of Social Sciences, 38(2), 185-195.

Ishtaiwa, F. F., \& Shana, Z. (2011). The use of Interactive Whiteboard by pre-service teachers to enhance Arabic Language teaching and learning. Learning and Teaching in Higher Education: Gulf Perspectives, 8(2).

Joshi, H. (2012). Towards transformed teaching: Engaging learners anytime, anywhere. UAE Journal of Education Technology and Learning, 3, 3-5.

Jwaifell, M., Abu-Omar, R., \& Al-Tarawneh, M. (2018). The readiness of Arabic language teachers for integrating flipped classroom: Case of Ma'an. International Journal of Instruction, 11(4), 855-868.

Kataw, Y. (2016). Teaching Arabic as a Foreign Language: The Role of Communicative Competence, Pragmatics, and Literacy (Masters). Utah State University.

Kennetz, K., \& Carroll, K. (2018). Language threat in the United Arab Emirates? Unpacking domains of language use. International Journal of the Sociology of Language, (254), 165-184.

Mosa, A., \& Kakehi, K. (2015). A way of Supporting Non-Arabic Speakers in Identifying Arabic Letters and Reading Arabic script in our new E-Learning System. EAI Endorsed Transactions On E-Learning, $2(6)$, e3. 
Muro, D. (2019). Languages killing languages: A rhetorical analysis of the media portrayal of the struggle between English and Arabic. The Undergraduate Research Journal at The University of Northern Colorado, $5(2)$.

Mustaffa, F., Sharif, N., Sirri, A., \& Hj-Salam, A. (2019). Features and teaching/learning activities used in educational android mobile applications to teach Quranic Arabic vocabulary. International Journal of Engineering and Advanced Technology, 8(5C), 1184-1187.

O'Neill, G. (2017). Multilingualism and occluded diversities within the superdiverse conditions of the United Arab Emirates: A study of the multiple language resources, practices, and ideologies of young Emirati women. (PhD). Macquarie University.

O'Sullivan, K, (2017) Second Language Acquisition in the UAE: Refocusing Attention on Teacher Professional Development. IOSR Journal of Humanities and Social Science, 22 (8), 70-78, http://dx.doi.org/10.2139/ssrn.3194376.

Palfreyman, D., \& Karaki, S. (2017). Lexical sophistication across languages: a preliminary study of undergraduate writing in Arabic (L1) and English (L2). International Journal of Bilingual Education and Bilingualism, 22(8), 992-1015 doi: 10.1080/13670050.2017.1326456

Palmer, J. (2007). Arabic diglossia: Teaching only the standard variety is a disservice to students. The Arizona Working Papers in Second Language Acquisition and Teaching, 14, 111-122.

Ryding, K. C. (2013). Teaching and learning Arabic as a foreign language: A guide for teachers (pp. xvi-277). Washington, DC: Georgetown University Press.

Sabbah, S. (2016). Is standard Arabic dying? (AWEJ). Arab World English Journal, 6(2). doi: http://dx.doi.org/10.2139/ssrn.2834376

Saiegh-Haddad, E., \& Ghawi-Dakwar, O. (2017). Impact of diglossia on word and non-word repetition among language impaired and typically developing Arabic native speaking children. Frontiers in Psychology, 8. doi: 10.3389/fpsyg.2017.02010

Seymour, J. (2016). Supporting bi-literacy among Emiratis in Dubai's private schools: An analysis of current Arabic language policy. Journal of Research in International Education, 6(3), 259-286.

Shendy, R. (2019). The limitations of reading to young children in literary Arabic: The unspoken struggle with Arabic diglossia. Theory and Practice in Language Studies, 9(2), 123. doi: 10.17507/tpls.0902.01

Taha, H. (2019). Arabic language education in the UAE: Choosing the right drivers. Education in The United Arab Emirates, 75-93. doi: 10.1007/978-981-13-7736-5_5

Wahdah, N. (2018). Dayakese students' beliefs about Arabic language learning and their relation to the language learning strategies. Alsinatuna, 4(1), 1. doi: 10.28918/alsinatuna.v4i1.1589

Wekke, I. (2015). Arabic teaching and learning: A model from the Indonesian Muslim minority. Procedia Social and Behavioral Sciences, 191, 286-290. doi: 10.1016/j.sbspro.2015.04.236

Zainuddin, N., \& Sahrir, M. (2016). Multimedia courseware for teaching Arabic vocabulary: Let's learn from the experts. Universal Journal of Educational Research, 4(5), 1167-1172. doi: 10.13189/ujer.2016.040529

Zakaria, Z.M., Atan, A. \& Robe'ah Yusuf, S.Y.M., (2019). Content knowledge competency of Arabic language teacher trainees during teaching practice. International Journal of Academic Research in Business and Social Sciences, 9(9). 